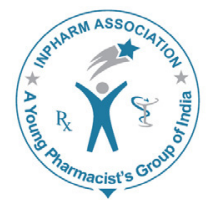

\title{
Assessment of medication adherence and knowledge regarding the disease among ambulatory patients with diabetes mellitus in Karachi, Pakistan
}

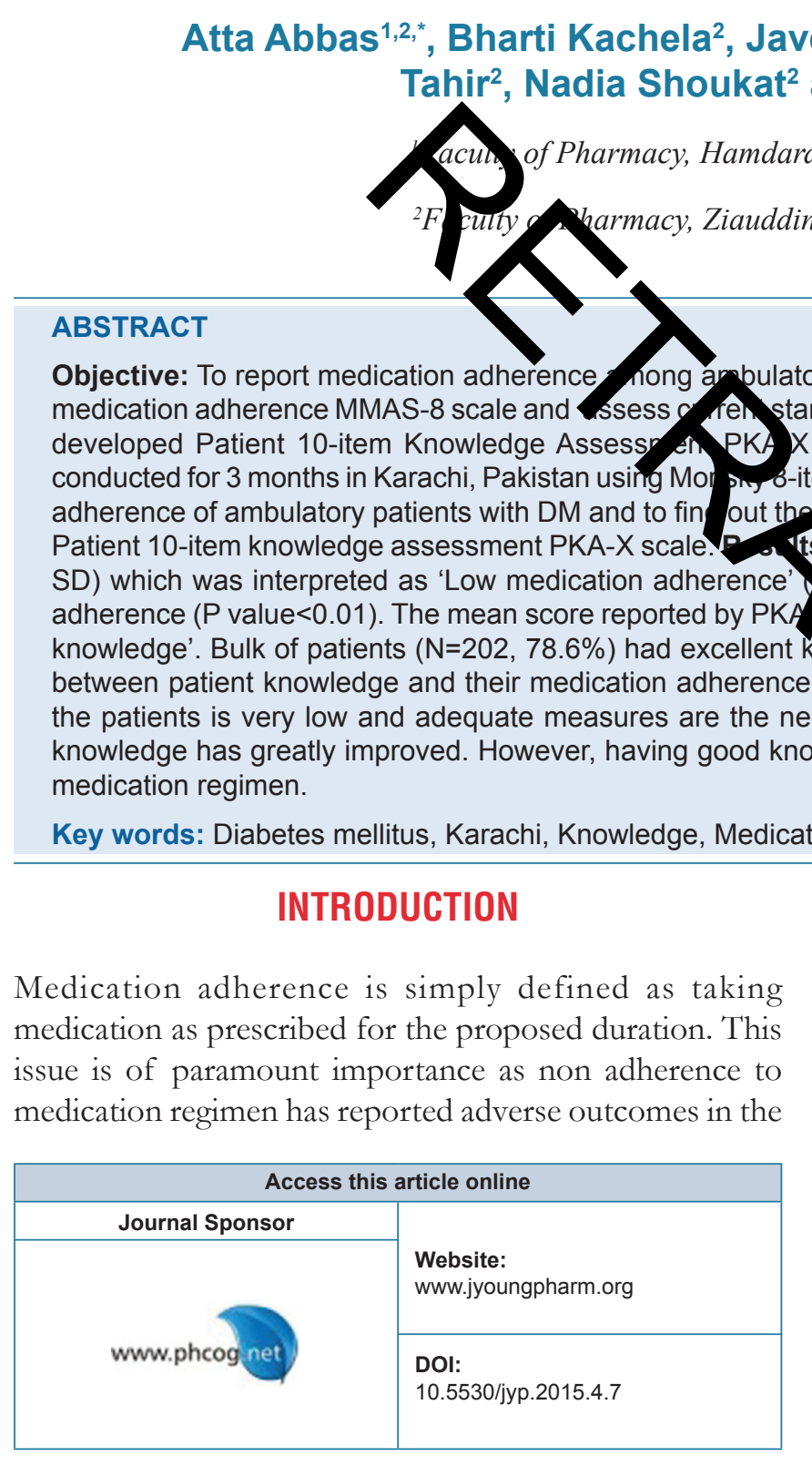

\section{JIVP}


The medication adherence of DM patients of Pakistan calculated by Morisky 8 item medication adherence scale is $\mathbf{4 . 6 9}$

\section{Low Adherence}

The standard of knowledge of DM patients of Pakistan calculated by Patient 10 item Knowledge assessment scale is $\mathbf{9 . 0}$

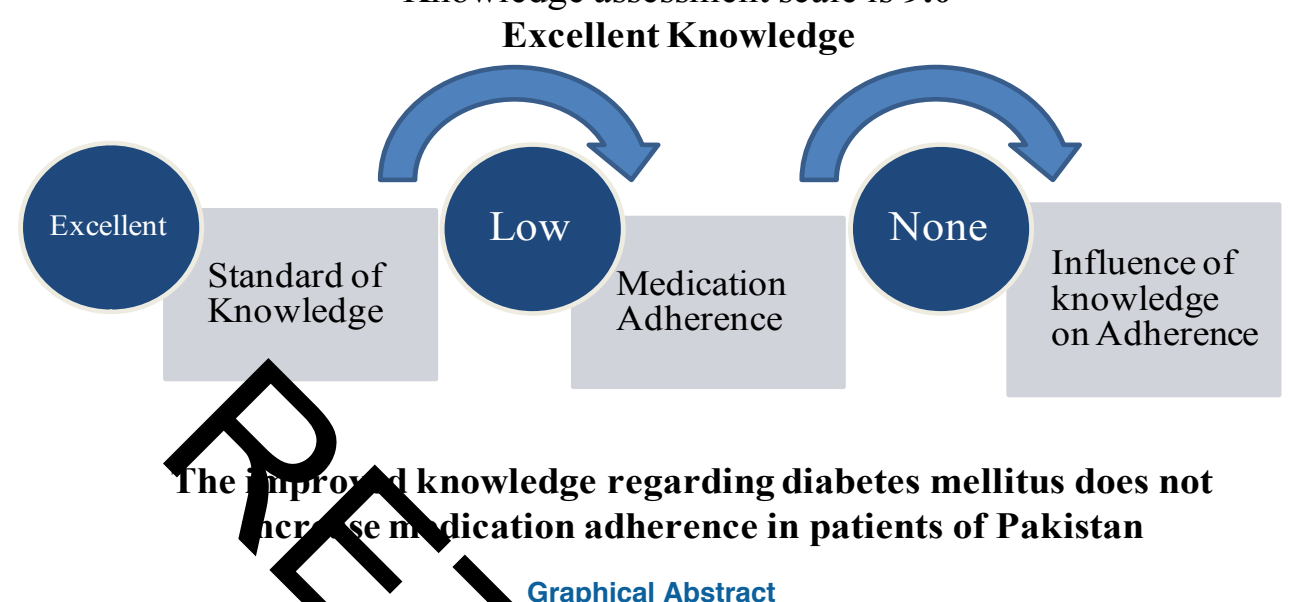

surge in the levels of glucose in the blood associated complications and risks along wi hyperglycemia. ${ }^{5}$ Studies have established the lip be ree DM and diseases such as hypertension HTN, Parkir on's disease PD, etc. ${ }^{6,7}$ Hence, the medication adheren DM is very important. Patients with DM are more prone to indulge in non adherence and studies report that these patients have the lowest adherence to their medication regimen. ${ }^{8}$ It is so because pharmacotherapy of DM includes challenging tasks such as remembering the medications, their frequency of administration and use of many drugs pose a challenge. Studies conducted on the subject indentify these issues as major barriers to compliance. Failure to adhere to diabetic medication regimen leads to poor glycemic control which further adds to disease and economic burden on the patients. ${ }^{3,10}$

Several tools have been established to measure the medication adherence in patients. One of the tools to measure adherence is the Morisky 8-item medication adherence scale or MMAS8 scale ${ }^{\circledR}$. The scale consisted of 8 simple questions tailored to be answered by patients. Each question carried a score of 0 or 1 depending upon the answer and sum of all 8 questions yield a final score which interpreted medication adherence of the patient. A score of 0 represented high adherence and 1-2 meant medium adherence to medication. Scores of 3-8 represented low adherence. ${ }^{11}$

The treatment of DM along with medications also encompass patient education which is aimed at providing basic disease information to the patient given that the disease is chronic i.e. lifelong and needs to be properly managed. Since diabetes mellitus DM requires patient counseling, physicians are deemed to perform this role. the past, various studies have reported low patient nowledge regarding DM and emphasized on improving pation-education regarding the disease. ${ }^{12}$ However, with cent de elopments in the health care system, pharmacists ave taken role of patient counseling to some extent an bein $\quad$ ognized by the health care professionals (HCPs), cuents the general public as well. ${ }^{13-16} \mathrm{It}$ is hypothesized ty th current standard of knowledge of DM patient as a matically improved now as compared to what it was

Pakistan currently ra $7_{\mathrm{k}} 7^{\mathrm{H}} \mathrm{n}$ the world in terms of DM disease burden. ${ }^{17,18}$ The health care system struggles to cope up and treat the disease population. ${ }^{14}$ The diabetic population of the country hardly gets treated and prescribed rationally for their ailments but adherence to medication is normally not a focal point of disease state management for the health care professionals (HCPs) and alike situation of the globe, non adherence to medications by patients was reported by earlier studies in Pakistan as well along with low knowledge. ${ }^{19,20}$ However, no study established a link between the two. The need to know about the medication adherence level and current knowledge of patients of DM and, if knowledge improves adherence becomes prime focus.

The present study was aimed at documenting the medication adherence among ambulatory patients of DM in Karachi, Pakistan by employing Morisky 8-item medication 
adherence MMAS-8 scale and reporting the current standard of knowledge of the diabetic patients regarding the ailment. It was done by developing a novel scale known as the Patient 10-item knowledge assessment PKA-X scale for recording patient knowledge in terms of scores and later interpreting them in context of knowledge standard.

\section{MATERIALS AND METHODS}

A quantitative cross sectional study was conducted for 3 months i.e. July 2014 to September 2014 with the aim of documenting the medication adherence of ambulatory patients with diabetes mellitus DM and reporting their standard of knowledge regarding the disease.

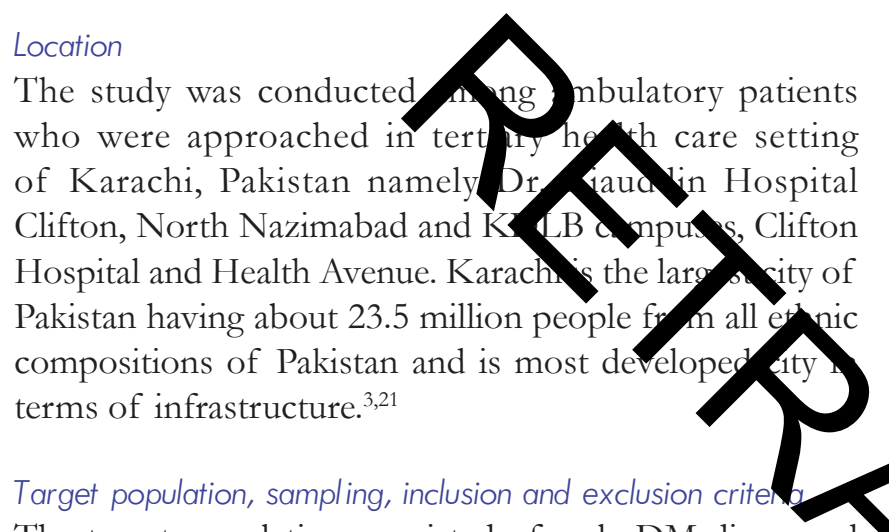
The target population consisted of only DM diagnosed patients. All other patients were excluded from the study. It was done through convenience sampling technique.

\section{Research instrument}

The research instrument consisted of a survey questionnaire adopted and translated to Urdu from the English version of Morisky 8 item Medication Adherence MMAS- 8 scale ${ }^{\circledR}$ where each variable carried a single score and sum of all the individual variable scores yield a final score which was interpreted in the context of medication adherence. A score of 0-1 represented high adherence and score of 2 represented medium adherence. Scores 3-7 represented low adherence and a score of 8 meant no adherence.

The research instrument used to assess the knowledge consisted of a data questionnaire containing questions related to the demographic information and diabetes awareness which was especially developed to measure patient knowledge. The scale was termed as Patient 10-item Knowledge Assessment PKA-X scale. It consisted of 10 research variables where each variable carried a score and sum of all the individual variable scores yield a final score which was interpreted in the context of patient knowledge. A score of 0-4 represented very low knowledge and score 5-7 represented low knowledge, however score of 7-8

meant adequate and score of 9-10 counted as excellent knowledge.

\section{Piloting and validation}

The research instrument was tested and validated by a team of experts for its suitability in a pilot study. The team of experts consisted of physician, clinical pharmacist and university professor. A pilot study was conducted before initiation of data collection and after validation of the research instrument, the study commenced. The research instrument was piloted on 23 patients; it took 11 minutes to fill in the responses. The results of the pilot study were not added in the main database.

Data analysis

The data thus collected was analyzed by SPSS v 20 (Statistical Package for Social Sciences version 20). The data was analyzed and central tendency, cross tabulation and chi square $\left(X^{2}\right)$ test was employed on the data. The results were expressed as mean $(X)$, standard deviation (SD), sample number $(N)$, percentages (\%) and significant 'P' values.

Patient consent

Prior to handing the instrument to the patients, they were briefed about the study and its objectives and their consent as obtained.

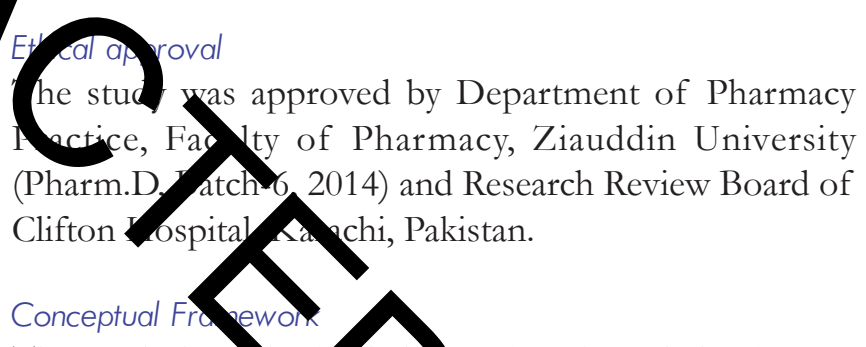

The study hypos the patient knowledge is now better than what is been the past and the medication adherence to DM therapy has improved. Furthermore, the study also hypothesized that improvement of patient knowledge has the potential to improve medication adherence of the DM patients.

\section{RESULTS}

A total of 300 questionnaires were sent and 257 questionnaires were returned back from the patients giving a response rate of $85.6 \%$. The results are expressed as demographic information, medication adherence information, patient knowledge and cross tabulation.

\section{Demographic information}

The study incorporated equal number of male and female patients with the numbers slightly tilted towards male

Journal of Young Pharmacists Vol $7 \bullet$ Issue $4 \bullet$ Oct-Dec 2015 
patients $(\mathrm{N}=135,52.5 \%)$ than female patients $(\mathrm{N}=122$, $47.5 \%$ ). The majority of patients belonged to the age above 45 years $(\mathrm{N}=147,57.2 \%)$ followed by a third proportion of the target group between the age of 30 to 45 years $(\mathrm{N}=89,34.6 \%)$ and less than a tenth between 16 to 30 years $(\mathrm{N}=21,8.2 \%$ ) (P value less than 0.01). Furthermore, the demographics revealed that an overwhelming majority of the patients was married $(\mathrm{N}=250,97.3 \%)$ and only few appeared single $(\mathrm{N}=7,2.7 \%)$ (P value less than 0.01). Bulk of the patients $(\mathrm{N}=245,95.3 \%)$ appeared to be educated while a small proportion $(\mathrm{N}=12,4.7 \%)$ appeared not $(\mathrm{P}$ value $<0.01)$. Major chunk of the patients were seen to suffer from type II DM $(\mathrm{N}=220,85.6 \%)$ and less than a fifth proportion of target segment $(\mathrm{N}=37,14.4 \%)$ were

\begin{tabular}{|c|c|c|c|c|}
\hline Attributes & Sample (N) & Percentage (\%) & Expected (N) & $P$ value \\
\hline \multicolumn{5}{|l|}{ Gender } \\
\hline Male & 135 & 52.5 & 128.5 & \multirow{3}{*}{$>0.05$} \\
\hline Female & 122 & 47.5 & 128.5 & \\
\hline Total & 257 & 100 & 257 & \\
\hline \multicolumn{5}{|l|}{ Age } \\
\hline Between 16 to & 21 & 8.2 & 85.7 & \multirow{4}{*}{$<0.01$} \\
\hline Between 30 tr & 89 & 34.6 & 85.7 & \\
\hline Above & 147 & 57.2 & 85.7 & \\
\hline Total & 257 & 100 & 257 & \\
\hline \multicolumn{5}{|l|}{ Social inforn } \\
\hline Single & & 2.7 & 128.5 & \multirow{3}{*}{$<0.01$} \\
\hline Married & & 97.3 & 128.5 & \\
\hline Total & & 100 & 257 & \\
\hline \multicolumn{5}{|l|}{ Education } \\
\hline Illiterate & & 4.7 & 128.5 & \multirow{3}{*}{$<0.01$} \\
\hline Educated & 245 & & 128.5 & \\
\hline Total & 257 & 100 & 257 & \\
\hline \multicolumn{5}{|l|}{ Phenotype } \\
\hline Type I Insulin dependent & 37 & & 128.5 & \\
\hline $\begin{array}{c}\text { Type II Non Insulin } \\
\text { dependent }\end{array}$ & 220 & & & \\
\hline Total & 257 & & & \\
\hline \multicolumn{5}{|l|}{ Duration of disease } \\
\hline Donotknow & 83 & 32.3 & & \multirow{6}{*}{$<0.01$} \\
\hline Since 1-6 month & 59 & 23 & & \\
\hline Since 6-12 month & 41 & 16 & & \\
\hline Since 1-3years & 59 & 23 & & \\
\hline Since $3-9$ years & 15 & 5.8 & 51 & \\
\hline Total & 257 & 100 & 257 & \\
\hline \multicolumn{5}{|l|}{ Comorbidity } \\
\hline No comorbidity & 18 & 7 & 51.4 & \multirow{6}{*}{$<0.01$} \\
\hline Cardiovascular disease & 167 & 65 & 51.4 & \\
\hline Respiratory disease & 5 & 1.9 & 51.4 & \\
\hline Musculoskeletal diseases & 4 & 1.6 & 51.4 & \\
\hline Retinopathy & 63 & 24.5 & 51.4 & \\
\hline Total & 257 & 100 & 257 & \\
\hline \multicolumn{5}{|l|}{ Diagnostic test } \\
\hline $\mathrm{Hb}_{\mathrm{A} 1 \mathrm{c}}$ & 0 & 0 & $0^{*}$ & \multirow{3}{*}{ ** } \\
\hline $\begin{array}{c}\text { Fasting Blood Glucose } \\
\text { and Random Blood } \\
\text { Glucose }\end{array}$ & 257 & 100 & $257^{\star}$ & \\
\hline Total & 257 & 100 & 257 & \\
\hline \multicolumn{5}{|l|}{ Medications } \\
\hline Insulin & 37 & 14.4 & 128.5 & \multirow{3}{*}{$<0.01$} \\
\hline Oral hypoglycemic agents & 220 & 85.6 & 128.5 & \\
\hline Total & 257 & 100 & 257 & \\
\hline
\end{tabular}


reported to suffer from type I DM (P value<0.01).

The results further reported that slightly more than a fifth proportion of the total patients $(\mathrm{N}=59,23 \%)$ were newly diagnosed with disease i.e. less than 6 months followed by exactly the same number of patients $(N=59$, $23 \%$ ) diagnosed with DM between 1-3 years. Some of the patients $(\mathrm{N}=41,16 \%)$ had DM since 6-12 months and a small proportion reported presence of disease since 3-9 years. A third of the target segment $(\mathrm{N}=83$, $32.3 \%$ ) appeared unaware of the duration of their disease ( $\mathrm{P}$ value $<0.01)$. Regarding comorbidity, majority of the patients suffered from cardiovascular comorbidity $(\mathrm{N}=167$, $65 \%$ ) followed by a quarter of the target segment with retinopathy $(\mathrm{N}=63,24.5 \%)$, few patients $(\mathrm{N}=5,1.9 \%)$ had respiratory diseases as co rbidity and very few $(\mathrm{N}=4,1.6 \%)$ suffered from $y$ sculg keletal diseases as a comorbidity. Less than a tanth o getsegment $(\mathrm{N}=18$, $7 \%$ ) had no comorbidity (P val $e<0$ 1). the patients $(\mathrm{N}=257,100 \%)$ were diagnosed $\mathrm{D}$ b he cenventional fasting blood glucose FBG and ram bloo plucose test RBG. Majority of the patients $(\mathrm{N}=220,85.6 \%)$ were on oral hypoglycemic agents followed by those patients $(\mathrm{N}=37,14.4 \%)$ on insulin ( $\mathrm{P}$ value $<0.01)$. The results of demographic information are summarized in Table 1.

\section{Medication adherence information}

Regarding the medication adherence information, the majority of the patients confessed that they sometimes forget to take their medications $(\mathrm{N}=168,65.4 \%)$ and a third segment of total patients $(\mathrm{N}=89,34.6 \%)$ did not forget $(\mathrm{P}$ value $<0.01)$. Less than half of the target group $(\mathrm{N}=124$, $48.2 \%$ ) revealed that they stop taking medications without informing their physician while the rest $(\mathrm{N}=133,51.8 \%)$ did not do so ( $\mathrm{P}$ value $>0.05$ ). In addition, more than half of the patients $(\mathrm{N}=42,55.3 \%)$ forgot medications whilst travelling followed by slightly less than half $(\mathrm{N}=115$, $44.7 \%$ ) responding contrarily ( $\mathrm{P}$ value $>0.05)$. However, an overwhelming majority of patients $(\mathrm{N}=195,75.9)$ were reported to take their complete medication the day before and while a quarter of the target segment $(\mathrm{N}=62$, $24.1 \%$ ) forgot $(\mathrm{P}$ value $<0.01)$. To the question of stopping

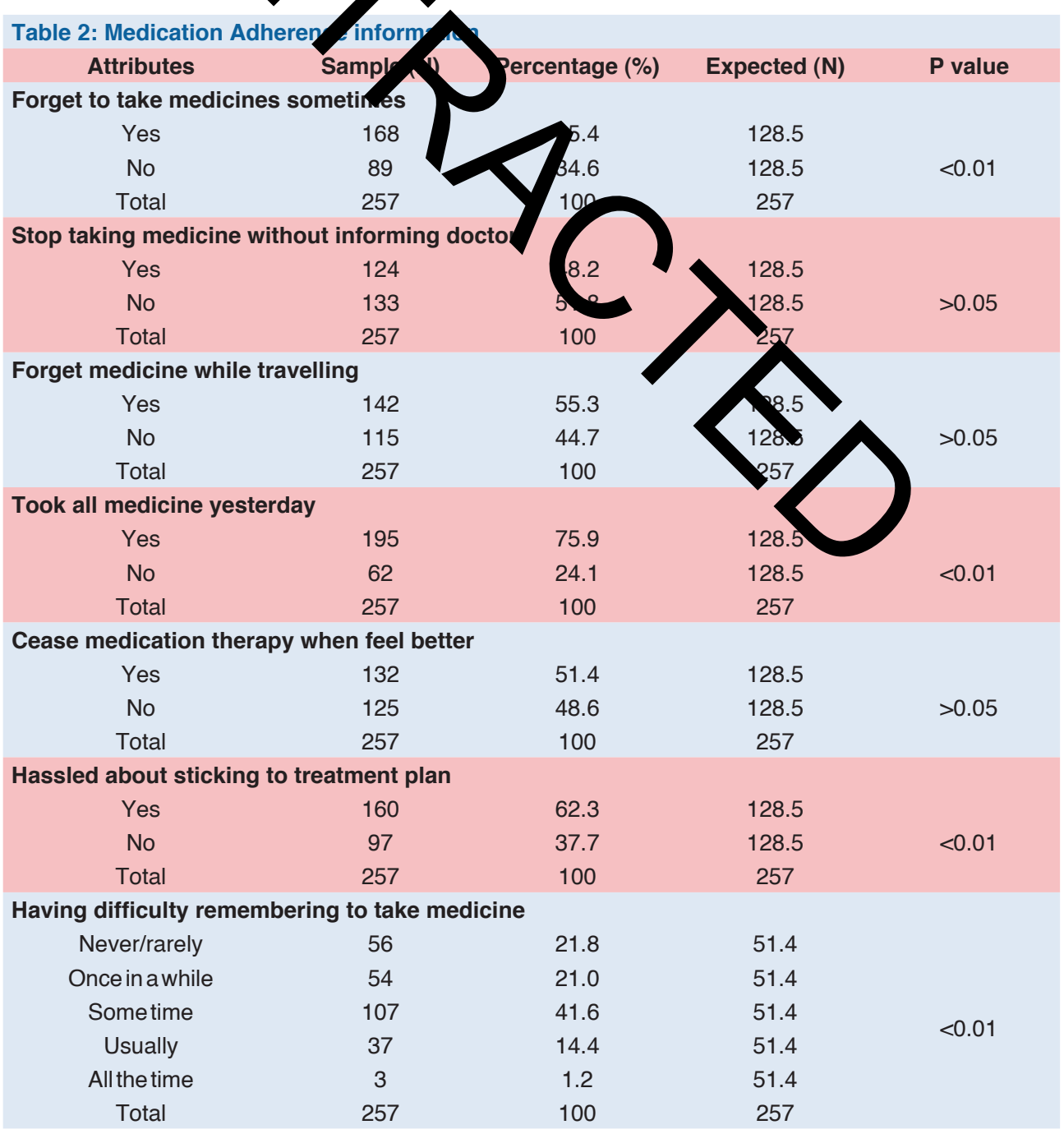




\begin{tabular}{|c|c|c|c|c|}
\hline Attributes & Sample (N) & Percentage (\%) & Expected (N) & P value \\
\hline \multicolumn{5}{|l|}{ MMAS-8 Score } \\
\hline $\begin{array}{c}\text { Morisky 8-item } \\
\text { Score } 1\end{array}$ & 22 & 8.6 & 32.1 & \multirow{9}{*}{$<0.01$} \\
\hline $\begin{array}{c}\text { Morisky 8-item } \\
\text { Score } 2\end{array}$ & 19 & 7.4 & 32.1 & \\
\hline $\begin{array}{c}\text { Morisky 8-item } \\
\text { Score } 3\end{array}$ & 25 & 9.7 & 32.1 & \\
\hline $\begin{array}{c}\text { Morisky 8-item } \\
\text { Score } 4\end{array}$ & 42 & 16.3 & 32.1 & \\
\hline $\begin{array}{c}\text { Morisky 8-item } \\
\text { Score } 5\end{array}$ & 56 & 21.8 & 32.1 & \\
\hline $\begin{array}{l}\text { Morisky 8-item } \\
\text { Score } 6\end{array}$ & 44 & 17.1 & 32.1 & \\
\hline $\begin{array}{c}\text { Morisky 8-item } \\
\text { Score } 7\end{array}$ & 34 & 13.2 & 32.1 & \\
\hline \multirow{2}{*}{$\begin{array}{c}\text { Morisky 8-item } \\
\text { Score 8 }\end{array}$} & 15 & 5.8 & 32.1 & \\
\hline & 257 & 100 & 257 & \\
\hline High & & 8.2 & 64.3 & \multirow{5}{*}{$<0.01$} \\
\hline $\begin{array}{c}\text { Medium } \\
\text { Adherence }\end{array}$ & & 7.0 & 64.3 & \\
\hline Low Adherence & & 79.4 & 64.3 & \\
\hline No Adherence & & 5.4 & 64.3 & \\
\hline Total & & 100 & 257 & \\
\hline
\end{tabular}

medication therapy in response to improving health, sl thtly more than half of the target group $(\mathrm{N}=132,5$ responded in favor while slightly less than half of the segment $(\mathrm{N}=125,48.6 \%)$ did not do so ( $\mathrm{P}$ value $>0.05)$. Bulk of patients $(\mathrm{N}=160,62.3 \%)$ felt a hassle in sticking to the pharmacotherapy of disease and more than a third proportion of the target segment $(\mathrm{N}=97,37.7 \%)$ did not feel any hassle in doing so $(\mathrm{P}$ value $<0.01)$. Furthermore, the respondents were asked if they had difficulty in remembering their medication and slightly less than half of the target group ( $N=107,41.6 \%)$ sometimes had this difficulty followed by those who seldom suffered from this problem $(\mathrm{N}=54,21.0 \%)$ and few $(\mathrm{N}=37,14.4 \%)$ who usually dealt with the problem. Fewer patients $(\mathrm{N}=3$, $1.2 \%$ ) had a regular issue remembering medications while a considerable number of patients $(\mathrm{N}=56,21.8 \%)$ never had any difficulty $(\mathrm{P}$ value $<0.01)$. The medication adherence information is summarized in Table 2.

The patients were handed Morisky 8-item medication adherence MMAS-8 questionnaire to record their medication adherence and the mean score was 4.69 $(X=4.69$, 1.9 SD) which was interpreted as Low medication adherence'. Bulk of the patients $(\mathrm{N}=56,21.8 \%)$ had score of 5 followed by some $(\mathrm{N}=44,17.1 \%)$ with score of 6 and few $(\mathrm{N}=34,13.2 \%)$ with score of 7 i.e. low adherence. Very few $(\mathrm{N}=15,5.8 \%)$ had a score of 8 i.e. no adherence. However, some of the patients $(\mathrm{N}=22,8.6 \%)$ had a score
1 i.e. high adherence while some $(\mathrm{N}=19,7.4 \%)$ had 2 medium adherence ( $\mathrm{P}$ value less than 0.01). In terms of collective score interpretation, major segment of the cient if s seen to have low adherence $(\mathrm{N}=204,79.4 \%)$ nd som $\mathrm{d}$ medium adherence to their medication , few were reported to have no adherence to their m acation $(\mathrm{N}=14,5.4 \%)$. Some patients $(\mathrm{N}=21$, $8.2 \%$ were als rep rted to have a high adherence to their medica on valueless than 0.01). The results are tabulated in

Patient knowledge

In addition to this, the patients were also investigated about their standard of knowledge regarding DM and it was reported that majority $(\mathrm{N}=221,86 \%)$ seemed aware of their overall health condition being related to the ailment and less than a fifth proportion of target segment $(\mathrm{N}=36,14 \%)$ seemed unaware $(\mathrm{P}$ value $<0.01)$. Almost all the patients $(\mathrm{N}=253,98.4 \%)$ responded that they experienced symptoms related to DM which prompted them to investigate the condition with a consultant and subsequently got diagnosed with DM however very few patients $(\mathrm{N}=4,1.6 \%)$ did not know how their disease was diagnosed (P value less than 0.01). Furthermore, they were asked about the symptoms experienced the most and majority had polyphagia $(\mathrm{N}=142,55.3 \%)$ followed by a quarter $(\mathrm{N}=65,25.3 \%)$ who had polydipsia and a fifth proportion of the target segment $(\mathrm{N}=50,19.5 \%)$ had 


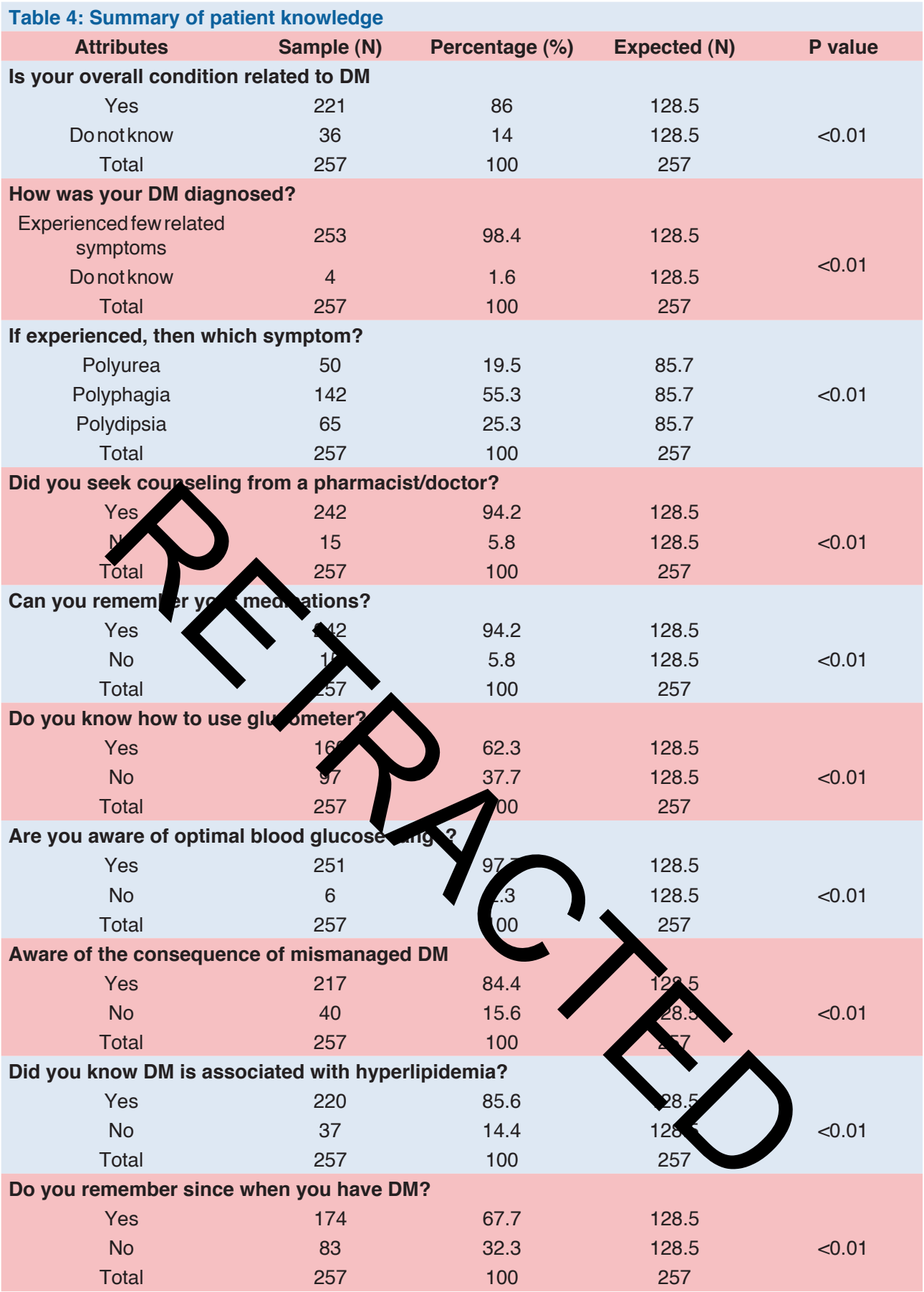

experienced polyurea the most $(\mathrm{P}$ value $<0.01)$. Bulk of the patients surveyed $(\mathrm{N}=242,94.2 \%)$ sought counseling from doctors/ pharmacists however few patients $(\mathrm{N}=15,5.8 \%)$ did not seek any counseling $(\mathrm{P}$ value $<0.01)$.

Almost all patients $(\mathrm{N}=255,99.2 \%)$ remembered their medication and very few $(\mathrm{N}=2,0.8 \%)$ did not ( $\mathrm{P}$ value $<0.01)$. Further to this, majority seemed aware of the optimal blood glucose range $(\mathrm{N}=251,97.7 \%)$ however some $(\mathrm{N}=6,2.3 \%)$ appeared to be unaware of the range $(\mathrm{P}$ value $<0.01)$. It was also observed that the majority of the patients knew how to use a glucometer at home $(\mathrm{N}=242$, $94.2 \%)$ followed by some patients $(\mathrm{N}=15,5.8 \%)$ who did not know how to use the glucometer (P value less than 0.01). To the question of awareness of consequences of mismanaged DM, an over whelming number of patients responded positive $(\mathrm{N}=217,84.4 \%)$ while some of patients $(\mathrm{N}=40,15.6 \%)$ seemed unaware of the consequences of mismanaged DM (P value $<0.01)$. Similarly, awareness of association of DM with hyperlipidemia was also tested, major segment of patients $(\mathrm{N}=220,85.6 \%)$ responded with positive answer but some of the patients $(\mathrm{N}=37$, 


\begin{tabular}{|c|c|c|c|c|}
\hline \multicolumn{5}{|c|}{ Table 5: Summary of PKA-X scale results } \\
\hline Attributes & Sample (N) & Percentage (\%) & Expected (N) & $P$ value \\
\hline \multicolumn{5}{|c|}{ Patient 10-item knowledge assessment (PKA-X) score } \\
\hline PKA-X Score 1 & 2 & 0.8 & 28.6 & \multirow{11}{*}{$<0.01$} \\
\hline PKA-XScore 2 & 1 & 0.4 & 28.6 & \\
\hline PKA-XScore 3 & 2 & 0.8 & 28.6 & \\
\hline PKA-XScore 4 & 0 & 0 & 28.6 & \\
\hline PKA-XScore 5 & 1 & 0.4 & 28.6 & \\
\hline PKA-X Score 6 & 7 & 2.7 & 28.6 & \\
\hline PKA-XScore 7 & 9 & 3.5 & 28.6 & \\
\hline PKA-XScore 8 & 34 & 13.2 & 28.6 & \\
\hline PKA-X Score 9 & 84 & 32.7 & 28.6 & \\
\hline PKA-X Score 10 & 117 & 45.5 & 28.6 & \\
\hline Total & 257 & 100 & 257 & \\
\hline \multicolumn{5}{|c|}{ Score interpretation } \\
\hline $\begin{array}{l}\text { Verylow } \\
\text { knowledge }\end{array}$ & 3 & 1.2 & 64.3 & \multirow{5}{*}{$<0.01$} \\
\hline Low kn & 11 & 4.3 & 64.3 & \\
\hline & & 16 & 64.3 & \\
\hline $\begin{array}{l}\text { Excelle } \\
\text { knowlec }\end{array}$ & & 78.6 & 64.3 & \\
\hline Total & & 100 & 257 & \\
\hline
\end{tabular}

Table 6: Summary of cross tabulation betwee medication adherence information

\begin{tabular}{|c|c|c|}
\hline Attributes & Male Patients (\%) & Female Pr \\
\hline Gender & $135(100)$ & $122(100)$ \\
\hline \multicolumn{3}{|l|}{ Age } \\
\hline Between 16 to 30 years & $11(8.1)$ & $10(8.1)$ \\
\hline Between 30 to 45 years & $41(30.3)$ & $48(39.3)$ \\
\hline Above 45 years & $83(61.4)$ & $64(52.4)$ \\
\hline Total & 135 & 122 \\
\hline \multicolumn{3}{|l|}{ MMAS-8 Score } \\
\hline Morisky 8-item Score 1 & $10(7.4)$ & $12(9.8)$ \\
\hline Morisky 8-item Score2 & $12(8.8)$ & $7(5.7)$ \\
\hline Morisky 8-item Score3 & $11(8.1)$ & $14(11.4)$ \\
\hline Morisky 8-item Score 4 & $23(17)$ & $19(15.5)$ \\
\hline Morisky 8-item Score 5 & $32(23.7)$ & $24(19.6)$ \\
\hline Morisky 8-item Score 6 & $19(14)$ & $25(20.4)$ \\
\hline Morisky 8-item Score 7 & $20(14.8)$ & $14(11.4)$ \\
\hline Morisky 8-item Score 8 & $8(5.9)$ & $7(5.7)$ \\
\hline Total & 135 & 122 \\
\hline \multicolumn{3}{|l|}{ Score interpretation } \\
\hline High Adherence & $10(7.4)$ & $12(9.8)$ \\
\hline Medium Adherence & $12(8.8)$ & $6(4.9)$ \\
\hline Low Adherence & $105(77.7)$ & $98(80.3)$ \\
\hline NoAdherence & $8(5.9)$ & $6(4.9)$ \\
\hline Total & 135 & 122 \\
\hline
\end{tabular}

$14.4 \%$ ) were not aware of the association ( $\mathrm{P}$ value $<0.01$ ). The patients were asked if they remember the time since they were diagnosed with DM, more than half of the target segment ( $N=174,67.7 \%$ ) was observed to remember the time since they contacted DM while a third proportion of target group $(\mathrm{N}=83,32.3 \%$ ) did not remember ( $\mathrm{P}$ value $<0.01)$. The results are summarized in Table 4 .
With the help of a newly formulated scale known as the Patient 10-item Knowledge Assessment PKA-X scale, the patients' standard of knowledge was quantified and terpreted. Each individual variable consisted of a score $\mathrm{f} 1$ and sum of all 10 variables yield a cumulative score of Thean score reported was $9.0(X=9.0, S D$ 1.4) which as inte reted as 'Excellent knowledge'. The summary of sults is tab ated in Table 5. Moreover, an overwhelming maynerty of nts $(\mathrm{N}=202,78.6 \%)$ was observed with their scor intery ted as excellent knowledge followed by a consider $\mathrm{nu}$ ber $(\mathrm{N}=41,16 \%)$ with adequate knowledge $\mathrm{DM}$ Few atients $(\mathrm{N}=11,4.3 \%)$ reported low knowledge nd al ost egligible number of patients $(\mathrm{N}=3,1.2 \%)$ had $y$ low 1 owledge ( $\mathrm{P}$ value less than 0.01). The results tab In Table 5.

Cross tabulation and chi square $\left(X^{2}\right)$ analysis

The cross tabulation of gender with medication adherence information revealed that female patients $(\mathrm{N}=12,9.8 \%)$ with MMAS- 8 score of 1 were reported to be more compliant to their medication regimen as compared to the males patients with same MMAS- 8 score $(\mathrm{N}=10,7.4 \%)$. However, males were more in number $(\mathrm{N}=12,8.8 \%)$ in case of medium adherence with MMAS- 8 score of 2 as compared to the females $(\mathrm{N}=7,5.7 \%)$. The results of medication adherence information with gender breakdown are summarized in Table 6.

The cross tabulation of age with medication adherence information revealed that the patients with age above 45 years were the most compliant to their medication regimen 


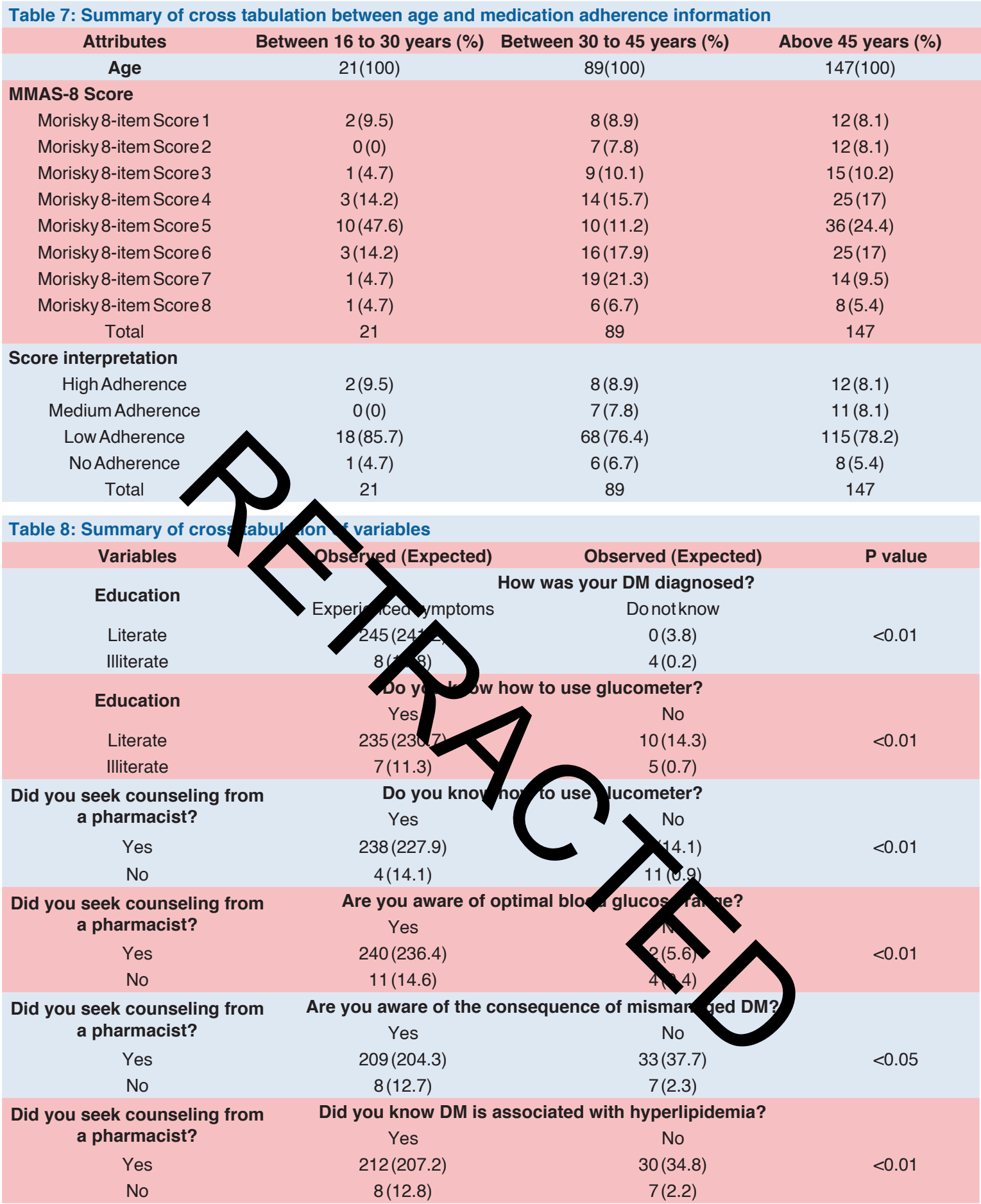

$(\mathrm{N}=12,8.1 \%)$ as compared to the patients falling in age groups between 16 to 30 years $(\mathrm{N}=8,8.9 \%)$ and between 30 to 45 years $(\mathrm{N}=2,9.5 \%)$. The results of medication adherence information with gender breakdown are summarized in Table 7.

Furthermore, it was observed that the variable of education was associated with the knowledge of DM diagnosis (P value $<0.05$ ) and knowledge about using a glucometer (P-value $<0.05)$. Moreover, the variable of seeking counseling from a doctor/pharmacist was also statistically associated with knowledge of using a glucometer $(\mathrm{P}$-value $<0.01)$, awareness of optimal blood glucose range $(\mathrm{P}$-value $<0.01)$, awareness of consequences of mismanaged DM (P-value $<0.05)$ and awareness of relation of hyperlipidemia with DM (P-value $<0.01)$. The detailed values of observed and expected counts are tabulated in Table 8 .

Lastly, the MMAS-8 scores were analyzed with PKA-X scores. The cross tabulation of both scores though was 


\begin{tabular}{|c|c|c|c|c|c|}
\hline \multirow{2}{*}{$\begin{array}{l}\text { Attributes } \\
\text { MMAS-8 Score } \\
\text { interpretations }\end{array}$} & \multicolumn{4}{|c|}{ PKA-X Scores interpretations } & \multirow[t]{2}{*}{$P$ value } \\
\hline & $\begin{array}{c}\text { Very low } \\
\text { knowledge }\end{array}$ & $\begin{array}{c}\text { Low } \\
\text { knowledge }\end{array}$ & $\begin{array}{c}\text { Adequate } \\
\text { knowledge }\end{array}$ & $\begin{array}{c}\text { Excellent } \\
\text { knowledge }\end{array}$ & \\
\hline \multicolumn{6}{|c|}{ Observed count $N$ (Expected count $N$ ) } \\
\hline High adherence & $0(0.2)$ & $1(0.9)$ & $3(3.4)$ & $17(16.5)$ & \multirow{4}{*}{$>0.05$} \\
\hline Medium adherence & $0(0.2)$ & $1(0.8)$ & $6(2.9)$ & $11(14.1)$ & \\
\hline Low adherence & $3(2.4)$ & $9(8.7)$ & $28(32.5)$ & $164(160.3)$ & \\
\hline No adherence & $0(0.2)$ & $0(0.6)$ & $4(2.2)$ & $10(11)$ & \\
\hline
\end{tabular}

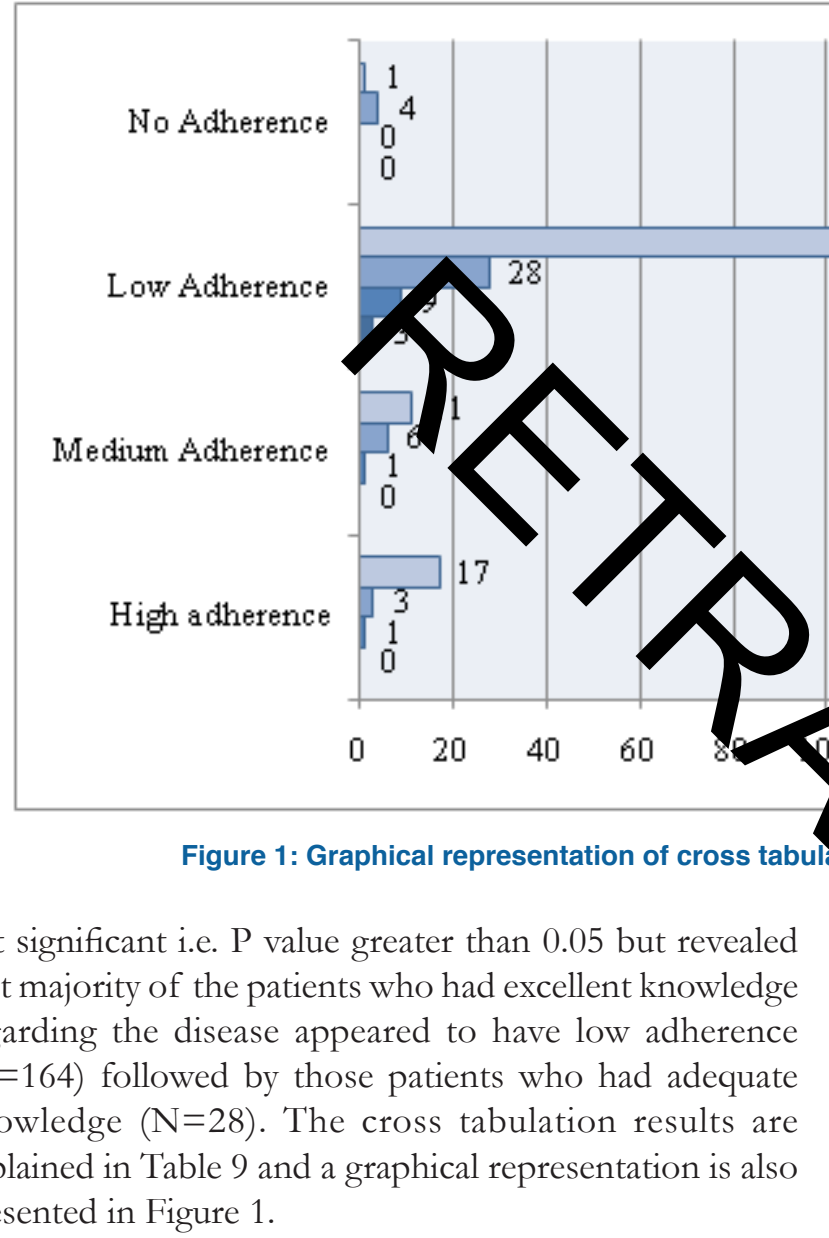

\section{DISCUSSION}

Medication adherence has always been an important debate in management of patients with chronic illnesses like diabetes mellitus DM. The current study investigated this issue in the ambulatory patients suffering from diabetes mellitus DM in Karachi, Pakistan with Morisky 8-item medication adherence MMAS-8 scale ${ }^{\circledR}$. The study incorporated 257 patients both male $(\mathrm{N}=135,52.5 \%)$ and female $(\mathrm{N}=122$, $47.5 \%$ ). In addition, the study also incorporated patients from different age groups i.e. between 16 to 30 years $(\mathrm{N}=21,8.2 \%)$, between 30 to 45 years $(\mathrm{N}=89,34.6 \%)$ and majorly above 45 years ( $\mathrm{N}=147,57.2 \%)$. The reason for latter being a major chunk in the age groups was the

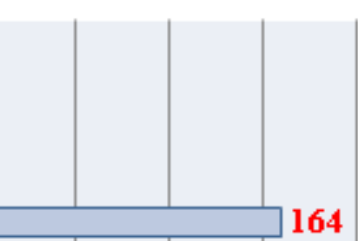

164

\section{$\square$ Ex cellent Knowledge}

$\square$ Adequate Knowledge

Low Knowledge

- Very low Knowledge 
as NICE recommended oral hypoglycemic agents to be prescribed as first line drugs in type II DM. ${ }^{7}$

It was reported in the study that the bulk of patients sometimes forget to take their medications $(\mathrm{N}=168,65.4 \%)$ at home and whilst travelling ( $\mathrm{N}=142,55.3 \%)$. Additionally, the study reported that sometimes the patients stop taking medications without the consent of the prescriber $(\mathrm{N}=124$, $48.2 \%)$ or when they feel better $(\mathrm{N}=132,51.4 \%)$ which is quite common in the country as there is no developed infrastructure of pharmaceutical care where a pharmacist can provide patient counseling in which the patients could be explained the consequence of non adherence and vice versa. Moreover, keeping in view the current pharmacy practice in the country, this issue of counseling though supported by the majority of th HCPs sometimes eyed with curiosity and suspicio $\mathrm{V}$ th prescribers, hence this suspicion is probably nind th practice which might be adding to the ignorand of e puents towards adherence to the prescribed DM re nen 13 Hever, this phenomenon needs to be further in stigated.

The study employed MMAS-8 scale to quatify th of adherence and it was reported that the mean $\mathrm{O}$ wa 4.69 $(X=4.69$, 1.9 SD) which interpreted as Low med anon adherence' thereby holding the test hypothesis invalid $T$ hi is a common problem among DM patients in the country as well as around the globe. ${ }^{22}$ This issue reiterates the need to create awareness about medication adherence among patients and develop mechanisms to ensure its propagation among the masses. A pharmacist as a diabetes mellitus DM disease educator can counsel the prescriber about the need to educate the patients at the time of their appointments emphasizing on the adherence to therapy. Similarly, the pharmacist can also counsel the patient directly during their prescription filling. ${ }^{4,15}$ This concept of pharmacist as a counselor has been reported by recent studies which revealed not only the patients but the general public also paints a very positive picture of clinical pharmacists improving patient outcomes. ${ }^{16,23}$

Encouragingly, the females sticking to their pharmacotherapy with high adherence reported by MMAS- 8 scale were more in number $(\mathrm{N}=12,9.8 \%)$ compared to their males counterparts $(\mathrm{N}=0,7.4 \%)$. However the latter were more in number $(\mathrm{N}=12,8.8 \%)$ as compared to females $(\mathrm{N}=7$, $5.7 \%)$ in case of medium adherence notwithstanding the high number of non adhering patients. One of the possible explanation to the problem can be linked to the fact that the males in Pakistani society are considered to be the sole bread earners and this might shift their focus from adherence issues to the job at hand as compared to the females who are mainly involved with household activities for most part. ${ }^{24}$ In case of age groups, patients with age above 45 years were the most compliant to their medication regimen $(\mathrm{N}=12,8.1 \%)$. It is quite evident that geriatric group is most affected by the disease and it shows compliance either due to prolonged experience in dealing with the disease, the age factor or retired life. ${ }^{25}$ The case with the others who were not compliant or showed less compliance such as adolescents can be linked to depression, parental influence and influence from the peers and friends. ${ }^{26}$ In this context depression has recently been reported as a major comorbidity of DM in Pakistan.

Furthermore, the study investigated the patients' standard of knowledge regarding DM. When asked about the disease, majority of the patients $(\mathrm{N}=221,86 \%)$ knew that their current health condition is related to their disease $(P$ value $<0.01)$. The trend was same when the patients were asked about the course of diagnosis of their ailment, an overwhelming majority reported to experience symptoms related to DM $(\mathrm{N}=253,98.4 \%)$ which prompted them to seek a diagnosis (P value $<0.01)$. Out of those who experienced symptoms, majority of patients $(\mathrm{N}=142$, $55.3 \%$ ) experienced polyphagia as a major sign ( $P$ value 0.01). An encouraging number of patients $(N=242$, $4.2 \%$ ) sought counseling from a doctor/ pharmacist $(\mathrm{P}$ valye 0.01 ) which is a new trend in Pakistan considering over health care dynamics and this observable fact ncores the indings of previous studies which report the all the country. ${ }^{13,15,16,23}$ Almost all patients $(\mathrm{N}=255.9 .2 \%)$ reported remembering their medications (P value 0.01 ad arrect way to use a glucometer at home $(\mathrm{N}=2$, 94 $\%$ (D value $<0.01)$ as well as optimal blood glucos ange 51, 97.7\%) (P value $<0.01$ ) Major segment kn the cy hsequence of mismanaged DM $(\mathrm{N}=217,84.4 \%,(\mathrm{P}$ ue $<0.01)$ and its association with elevated cholesterol (hyperlipidemia) $(\mathrm{N}=220,85.6 \%)$ ( $\mathrm{P}$ value $<0.01)$. Surprisingly a third of the target segment $(\mathrm{N}=83,32.3 \%)$ did not know about the duration of their illness however, majority $(\mathrm{N}=174,67.7 \%)$ was aware of the duration ( $\mathrm{P}$ value $<0.01)$.

The patients' standard of knowledge was investigated using a newly designed scale known as the Patient 10-item Knowledge Assessment PKA-X scale. The mean score reported was $9.0(X=9.0, S D$ 1.4) which was interpreted as 'Excellent knowledge' which holds the test hypothesis valid in this case (P value <0.01).

An overwhelming majority of patients $(\mathrm{N}=202,78.6 \%)$ was observed with their scores interpreted as excellent knowledge followed by a considerable number $(\mathrm{N}=41,16 \%)$ with 
adequate knowledge of DM. Few $(\mathrm{N}=11,4.3 \%)$ reported low knowledge and almost negligible number of patients $(\mathrm{N}=3,1.2 \%)$ had very low knowledge ( $\mathrm{P}$ value $<0.01)$. This shows that the standard of knowledge of patients with DM regarding their disease has significantly improved which can be attributed to the recent inclusion of pharmacists in the health care system of the country. ${ }^{27}$ Although, the extent to which pharmacists are responsible for improved DM patient knowledge regarding their disease needs to be verified.

Further to this, the association of variable of education with variable of diagnosis of $\mathrm{DM}$ was statistically significant $(\mathrm{P}<0.01)$. The patients who were educated could decipher the symptoms which ultimately prompted them to get tested for the disease. Awareness of correct method of glucometer usage was found to statistically significant $(\mathrm{P}<0.01)$ with the variable of acat $\mathrm{n}$ and counseling by pharmacist $(\mathrm{P}<0.01)$. The atien ho were educated or sought counseling could learn te co ect ethod to use the glucometer at home. The ay old atreness of optimal blood glucose range, conseq nces of $\mathrm{mt}$ anaged DM and association of DM with erevated holesterol (hyperlipidemia) was also significantly aciate
the doctor/ pharmacist counseling with $\mathrm{P}$ $<0.01,<0.05$ and $<0.01$ respectively. It means that rose patients were explained about the matter by a healt ca professional HCP.

As a final point, the MMAS- 8 scores were analyzed with PKA-X scores and results revealed that patients with excellent knowledge regarding the disease appeared to have low medication adherence which ultimately lead to the conclusion that knowledge about the disease may not influence the adherence to medication (P value $>0.05$ ) and subsequently rejected the test hypothesis. Hence there are some more influential factors affecting medication adherence. The investigators recommend further studies to be carried out in this regard.

\section{CONCLUSION}

The medication adherence of the patients is very low and adequate measures are the need of the hour to address this issue. The standard of knowledge of diabetic patients has great greatly improved and it is evident that presence of a pharmacist influence patient knowledge about the disease, its treatment and management. However, having good knowledge about the disease does not guarantee adherence to medication regimen.

It is very important to identify the potential local barriers to medication adherence and further digging into the matter is required, moreover prescribers need to raise this issue with their patients during their appointments, customize the treatment regimen and build a strong relationship with the patients. The employment of pharmacists as disease educators is essential for creating awareness about the issue and its consequences.

\section{ACKNOWLEDGEMENT}

The authors acknowledge and express their gratitude to Miss Khizra Ali for her assistance in data analysis and tabulation.

\section{CONFLICT OF INTEREST}

e authors declare no conflict of interests exists.

\section{SUPPORTING INFORIMATION}

bis article $\mathrm{h}$ based on the research project undertaken as a Bacher s 1 sesis for partial fulfillment of Doctor of Phar acy (Pb D) degree at Faculty of Pharmacy, Ziauddin Uni aty, Machi, Pakistan. No funding was obtained fo

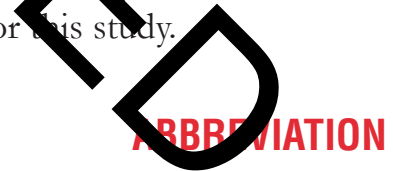

DM: Diabetes Mellitus

MMAS-8: Morisky 8-item Medication Adherence Scale

PKA-X: Patient 10-item Knowledge Assessment Scale

HCP: Health Care Professionals

\section{Highlights of Paper}

- The medication adherence of the diabetic patients of Pakistan is very low.

- The standard of knowledge regarding Diabetes Mellitus DM has greatly improved among the patients.

- However, having good knowledge about the disease does not guarantee adherence to medication regimen. 


\section{Author Profile}

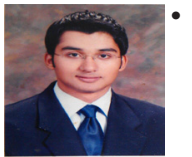

Dr. Atta Abbas: Is currently an Assistant Professor in the Department of Pharmacy Practice at the Faculty of Pharmacy, Hamdard University and Advisory Board Member at Clifton Hospital, Karachi, Pakistan. His research interests are mainly in the area of Pharmacotherapy, Public Health and Social Pharmacy.

\section{REFERENCES}

1. Michael P, Chris Ho, Bryson L, John Rumsfeld S. Medication Adherence: Its Importance in Cardiovascular Outcomes. Circulation 2009; 119(23): 3028-35.

2. Bussell, Marie T, Brown, Jennifer K. Medication Adherence: WHO Cares? Mayo Clin Proc. 2011; 86(4): 304-14.

3. Mudassar Hussain, Syed Baqir Shyum Naqvi, Maqsood Ahmed Khan, Mehwish Rizvi, Shazia Alam, Atta Abbas, et al. Direct cost of treatment of diabetes mellitus type 2 in Pakistan. Int J Pharm Pharm Sci. 2014; 6(11): 261-4.

4. Mehwish Rizvi, Sidra Tanwir, Atta .obo. Arif Sabah, Zeb-un-Nisa, Imran Mustaq, et al. Epidemi acal s dy of diabetes mellitus DM among different ethic sumen opylation in Pakistan: A nationwide ethnographical study. I J Res in Pharmacother. 2014; 3(1): 40-5.

5. Atta Abbas, Arif Sabah, Farrukh R riq A yed, Sra Tanwir. Views of health care professionals re rding differe types of commercially available insulins. J Bioto hnol So Res 2014; 1(1): 1-8.

6. Hania Fawad, Mahnoor Maqsood, Atta Abbas. The as ciath between type-Il diabetes mellitus and hypertension: A Ase opor Int J Allied Med Sci Clin Res. 2014; 2(3): 182-5.

7. Atta Abbas. The association between type II diabetes mellit s and Parkinson's disease: A case report. El Mednifico J. 2014; 2(1),20

8. Curkendall SM, Thomas N, Bell KF, Juneau PL, Weiss AJ. Predictors of medication adherence in patients with type 2 diabetes mellitus. Curr Med Res Opin. 2013; 29(10): 1275-86.

9. Odegard PS, Gray SL. Barriers to medication adherence in poorly controlled diabetes mellitus. Diabetes Educ. 2008; 34(4): 692-7.

10. Joan $\mathrm{N}$ Kalyango, Erisa Owino and Agatha P Nambuya. Nonadherence to diabetic treatment at Mulago Hospital in Uganda: prevalence and associated factors. Afr Health Sci. 2008; 8(2): 67-73.

11. Morisky Medication Adherence Scales. (Online). Available :http://c. ymcdn.com/sites/www.aparx.org/resource/resmgr/Handouts/ Morisky_Medication_Adherence.pdf. [Online]

12. Jabbar AZ, Ebrahim MA, Mahmood K. Standard of Knowledge about their Disease among Patients with Diabetes in Karachi, Pakistan. JPMA. 2001; 51(216): 216.

13. Adnan S, Tanwir S, Abbas A, Beg AE, Sabah A, Safdar H, Moin $\mathrm{M}$. et al. Perception of physicians regarding patient counselling by pharmacist: A blend of quantitative and qualitative insight. Int J Pharm Ther. Ther. 2014; 5(2): 117-21.

14. Atta Abbas Naqvi, Ken McGarry. Polypharmacy in Pakistan. Germany. Lap Lambert Academic Publishing Corp; 2014. ISBN 978-3-659-56506-9.
15. Nabeel Khan, Atta Abbas, Ken McGarry, Sadaf Shahid Perceptions and experiences of physicians regarding integration of clinical pharmacists in health practices: A survey of hospitals of Karachi, Pakistan. Int J Allied Med Sci Clin Res. 2014; 2(3): 222-34.

16. Atta Abbas, Amna Shah, Nabeel Khan, Hira Nasir, Muhammad Hassan Khan. Perceptions of patients' caregivers regarding clinical pharmacists and their practice in a developing country. Int J Pharm Pharm Sci. 2015; 7(2): 168-73.

17. WHO ranks Pakistan 7 th on diabetes prevalence list. The Nation. 2008 Nov 15. Cited: 2015 Jan 17. ZAvailable:http://nation.com. pk/karachi/15-Nov-2008/WHO-ranks-Pakistan-7th-on-diabetesprevalence-list. [Online]

18. Mohammad Akmal Khan, Sayed Mohammad Sultan, Rubina Nazli, Tasleem Akhtar, Mudasar Ahmad Khan, Nabila Sher, et al. Depression Among Patients With Type-II Diabetes Mellitus. J Coll Physicians Surg Pak. 2015; 24(10): 770-1.

19. Fawad Taj, Mansoor Tanwir, Zarmeneh Aly, Ameer Ali Khowajah, Asma Tariq, Fahd Khalid Syed, et al. Factors associated with nonadherence among psychiatric patients at a tertiary care hospital, Karachi, Pakistan: a questionnaire based cross-sectional study. J Pak Med Assoc. 2008; 58(8): 432-6.

. Jabbar AZ, Ebrahim MA, Mahmood K. Standard of Knowledge about their Disease among Patients with Diabetes in Karachi, Pakistan. JPMA. 2001; 51(1): 216.

21 Karao Wikipedia. Available: http://en.wikipedia.org/wiki/Karachi. Marha is Salihah Omar, Kong Lai San. Diabetes knowledge and adherence mong geriatric patient with type 2 diabetes mellitus. Pharm rm Sci. 2014; 6(3): 103-6.

23. Atta Aby s, AmnarShah, Nabeel Khan. The need to seek public opinif cowards all pharmacists in Pakistan. Med Sci. 2014; 14(57): 54-

24. Shoaib Ak ar, Ay ha Kanhif, Ahmed Arif M, Afzal Khan. Impact of Long Wor g Hours nily Wellbeing of Corporate Family. World Appl Scl 20' , 16(9). 302-7.

25. Jing Jin, Grant Ea ard Skla Vernon Min Sen Oh, Shu Chuen Li. Factors affecting peutic compliance: A review from the patient's perspective. Ther Clin Risk Manag. 2008; 4(1): 269-86.

26. Laura Cox and Jane Hunt. Factors that affect adolescent's adherence to diabetes treatment. Nurs Child Young People. 2015; 27(1): 16-21.

27. Atta Abbas, Nabeel Khan. Clinical trials involving pharmacists in Pakistan's healthcare system: A leap from paper to practice. Pharmacy 2014; 2(3): 244-7. 